\title{
Humor e estereótipos no YouTube: uma análise multimodal crítica do anúncio audiovisual "Slow Dove men + care"1
}

Roziane Keila Grando*

\section{Resumo}

O presente artigo teve como objetivo identificar como se constrói multimodalmente a noção e a relação de gênero no anúncio audiovisual que circulou na internet, mais especificamente no YouTube, e foi amplamente divulgado em 2013, intitulado Slow: Dove Men + Care. Para tanto, foi utilizada, como abordagem teórico-analítica, a Semiótica Social. A análise multimodal foi direcionada por meio das três metafunções da Gramática do Design visual (Reading Images): ideacional, interpessoal e textual. Com a discussão proposta acerca dos gêneros e a análise do anúncio, percebeu-se que à proporção que esses estereótipos são criados e representados pela mídia, também são evidenciadas formas de ser/atuar que a sociedade preconiza, já que estão imbuídos nesses discursos comportamentos, valores e atitudes acerca de um ou outro gênero, formulando posturas de masculinidade ou feminilidade e relações de poder entre eles.

Palavras-chave: Multimodalidade. Gênero. Anúncio audiovisual. Estereótipos.

\section{Introdução}

Atualmente, o fluxo de imagens que circulam nas práticas sociais faz com que as modalidades (imagem estática, imagem em movimento) e seus modos (visual, sonoro) sejam vastamente utilizados em vários segmentos, inclusive no contexto publicitário.

Dessa forma, a publicidade busca sempre formas de venda e comercialização de produtos e serviços para atingir um percentual considerável do público. Não é incomum nos depararmos com aqueles comerciais feitos para marcas de

\footnotetext{
Mestre em Linguística pela Universidade Federal de Santa Catarina - Ufsc (2011). Doutoranda em Linguística Aplicada pela Universidade Estadual de Campinas (Unicamp). Atualmente, é professora substituta do Curso de Letras Português e Literatura Portuguesa da Universidade Estadual do Centro-Oeste (Unicentro). Tem experiência na área de linguística, com ênfase em linguística aplicada, atuando nos seguintes temas: formação de professores, novos e multi letramentos, TIC e Educação a distância. E-mail: kekegrando@ yahoo.com.br
}

Data de submissão: nov. 2018 - Data de aceite: mar. 2019 http://dx.doi.org/10.5335/rdes.v15i1.8889 
carro, de margarina, ou mesmo do creme dental em que se vende "o produto dos sonhos" com certos estereótipos. Nesse entremeio estão aqueles de produto de limpeza, ou comerciais de cerveja e outras bebidas que colocam a mulher no palco da sensualidade e do desejo em um tom sexista. A lista de situações que representam a mulher de forma estereotipada é ampla, mas, neste artigo, vamos nos deter às propagandas de shampoo, que geralmente têm personagens femininas sendo retratadas com cabelos perfeitos, longos, brilhantes e sedosos.

Empresas como a Ogilvy \& Mather $^{2}$ fazem pesquisas de mercado ${ }^{3}$ para entender quais práticas e rotinas estão envolvidas no público-alvo. Foi o caso da campanha de um produto da Unilever, "Dove Men+Care": Shampoos e condicionadores", em que, conforme a equipe de produção observou, por meio de pesquisa mercadológica, os homens aumentaram o uso dos produtos para cuidados pessoais com a beleza. No caso desse anúncio, o objetivo foi conquistar um público masculino mostrando que a "preocupação com os fios também faz parte da rotina masculina e que, para isso, existem produtos adequados às suas necessidades" 5 . Em contrapartida, à proporção que esses estereótipos $^{6}$ são criados e representados na mídia, também são evidenciadas formas que a sociedade preconiza, já que estão imbuídos nesses discursos comportamentos, valores e atitudes acerca de um ou outro gênero, formulando posturas de masculinidade ou feminilidade e relações de poder entre eles.
Situações como essas mostram a natureza dinâmica da comunicação numa sociedade em que diferentes modos de significar o mundo são experimentados. Nesse sentido, a Semiótica Social funciona como uma metalinguagem que se utiliza da descrição de recursos semióticos e que permite observar o que se diz e faz com imagens (e outros meios de comunicação visuais), bem como permite interpretar as coisas que as pessoas dizem e fazem com imagens (JEWITT; OYAMA, 2004).

Por meio dos modos visual e sonoro as propagandas como a que iremos analisar, de forma humorada, remontam a estereótipos sociais do que é coisa de homem e o que é coisa de mulher. Por isso, a importância da formação de um leitor por meio do letramento crítico que observe tais estereótipos. Nesse sentido, adotando como construto teórico-analítico a Semiótica Social (KRESS; VAN LEEUWEN, 2006 [1996]); JEWITT; VAN LEEUWEN, 2008), nosso intuito é identificar a noção e a relação de gênero constituída de forma multimodal no anúncio Slow: Dove Men + Care ${ }^{7}$. Para tanto, discutiremos correlativamente a noção de gênero, pautados em autores como Butler (2003), Benhabib (1986; 1999), Cameron (2010) e Moita Lopes (2001; 2006).

Na próxima seção, discutiremos brevemente a abordagem do gênero. $\mathrm{Na}$ seção seguinte, explicaremos o anúncio e o YouTube como mídia que corrobora para a circulação desses discursos. $\mathrm{Na}$ 
penúltima seção, abordaremos o construto teórico da Gramática do design visual e, por fim, mostraremos a análise e a discussão acerca do anúncio Slow: Dove Men + Care, por meio das metafunções propostas pelos autores Kress e Van Leeuwen (2006 [1996]).

\section{A abordagem do gênero}

Ao iniciar as discussões sobre gênero, queremos entendê-lo conforme Cameron (2010), para quem as normas culturais que definem masculinidade e feminilidade suscitam condições as quais fazem com que o gênero seja constantemente reafirmado e publicamente exibido por meio de performances repetidas. Assim, tendo em vista o anúncio do produto Dove Men + Care, percebemos que, por meio de recursos intertextuais, as práticas de como as propagandas de comercial de shampoo, protagonizadas quase sempre por mulheres, são reificadas como performances repetidas.

É nesse sentido que Butler (2008, p. 59) defende que "gênero é a estilização repetida do corpo, um conjunto de atos repetidos dentro de uma estrutura rígida e reguladora que se consolida, com o passar do tempo, produzindo o que aparenta ser substância, uma espécie natural de ser". Aquilo que se consolida com o passar do tempo é regularizado no anúncio da empresa Ogilvy e Mather ao se criticar os estereótipos de comerciais de shampoos como sendo feminino (já que, até então, homens usam qualquer outro shampoo), o que implica que Diego (personagem do anúncio), por usar cosmético feminino, estaria reproduzindo uma performance de comercial de shampoo de mulher.

Condutas como essas são para Butler (1990) comportamentos generificados. Isto é, tornar-se mulher (ou homem) não se estabelece definitivamente quando nascemos, ou apenas enquanto somos crianças. Culturalmente falando, ser homem ou ser mulher necessita de uma confirmação pública inalterável, por meio da repetição de ações nas práticas sociodiscursivas definidas por normas convencionalizadas de forma histórica e social, nas quais se definem a masculinidade e feminilidade.

No mesmo contorno, chamamos Benhabib (1987, p. 91), ao afirmar que gênero-sexo é "um modo essencial pelo qual a realidade social é organizada, simbolicamente dividida e vivenciada na prática”. Para tanto, é preciso compreender que divisões como ter shampoo específico para homens funcionam como estratégia do consumo para se aproveitarem as oportunidades do mercado a se agradar um público específico e criar outras formas de divisão, as quais ainda não foram institucionalizadas e divididas simbolicamente.

Para Connel (2000, p. 12), "os corpos dos homens são entendidos como partes constitutivas de suas masculinidades, não no sentido de um essencialismo biológico, mas no sentido de que são 'definidos e disciplinados' pela ordem do 
gênero da sociedade”. Isso não implica discutir o discurso da propaganda como sexista somente, já que é um produto final de uma prática. Contudo, implica questionar a parte de institucionalização do produto para o mercado, desde o momento da escolha feita pela Unilever se posicionar num segmento do mercado buscando a exclusividade de um público, o que acaba por proporcionar espaço para a exclusão em diferentes contextos e que desvela vários desdobramentos.

Scott Kiesling (2007), ao estudar a masculinidade expressa por meio da linguagem, afirma que discursos culturais de masculinidade compreendem uma masculinidade hegemônica. Para o autor, "Masculinidade é expressa em linguagem por meio de recursos de linguagem indicial, de discursos culturais de masculinidade, ou por meio de recursos diretamente indiciais de certos tipos de homens" (KIESLING, 2007, p. $659^{8}$ ). Neste sentido, para a autora, nem sempre é fácil descobrir quais são esses índices ${ }^{9}$ enquanto recursos linguísticos. Assim sendo, pensamos que, ao olhar essa propaganda como uma modalidade de imagem em movimento, multimodal e, tomarmos a gramática do design visual, ela nos oferecerá uma metalinguagem para podermos pensar nesses índices que corroboram um discurso da diferença na sociedade.

Portanto, abordar o gênero nesse contexto não é pensar homens como sujeitos não marcados, mas como pessoas que, como as mulheres, estão sujeitos a estereótipos sobre gênero, língua e recursos semióticos que vivem numa luta de poderes para manter a aparência de masculinidade. E olhar para esses movimentos é ver que são práticas sociais das quais participamos na vida cotidiana, carregando no seu interior convenções do que é masculinidade e feminilidade, realizando-se sempre por meio da linguagem.

\section{A propaganda criativa e os anúncios no YouTube}

Cada vez mais a Mídia, a Informação e a Cultura dependem de tecnologias para sua distribuição. As mudanças tecnológicas são contínuas e facilitam a difusão massiva de textos, imagens, notícias e vídeos. Aquele estilo de anúncio que, antes estava nas páginas do jornal diário impresso, agora está na sua tela a cada clique que faz para procurar um vídeo no YouTube. Assim sendo, as novas e velhas mídias se complementam, como diria Manovich (2002).

A mídia social ${ }^{10}$ YouTube é um site que permite que os usuários carreguem e compartilhem vídeos em formato digital $^{11}$. Trata-se de uma ferramenta hipermídia que permite que no próprio conteúdo o usuário crie entrada de links que possam direcionar a outros sites ou vídeos. Lançado em 2006, o YouTube evoluiu em alguns recursos e, com a compra desse site pelo Google, o mercado publicitário ficou mais aquecido, justamente por permitir publicidade de vídeos 
por meio do Adsense ${ }^{12}$, que consiste num serviço de publicidade que é oferecido pelo Google. Nele, os proprietários de websites podem se cadastrar para exibir anúncios em texto, imagem e vídeo. Assim, o Google exibe os anúncios e gera lucro com base na quantidade de cliques e visualizações de usuários.

Os pesquisadores da área de comunicação, mais especialmente da Publicidade e Propaganda, tais como Sirrors (2001) e Mano (2009) discutem a inserção das mídias no mercado publicitário. Conforme Sirrors (2001), elas são mídias cibernéticas, já que se trata de um tipo de mídia que requer um computador e todos os meios de comunicação que estão relacionados ao computador e a redes, funcionando como uma supervia da informação. Dessa forma, os planejadores de mídia buscam modos fáceis e rápidos de fazer as mensagens publicitárias chegarem aos consumidores. Do mesmo modo, a supervia da informação é que permite a velocidade e a facilidade da distribuição.

Dadas as explicações acerca da distribuição, é preciso compreender o processo de produção do material audiovisual. Um dos elementos estratégicos na criação publicitária é criatividade, mesmo porque o anúncio em pauta neste artigo recorre, algumas vezes, a um tom criativo da mensagem. Ao pensar na criatividade, a ela está aliado o humor. Conforme Arens, Shaefer e Weigold (2013), o foco na escolha dos elementos visuais é uma fase fundamental do processo de criação e, tal fase determina a eficácia da execução de uma "grande ideia". Dessa forma, o humor é um elemento visual que, se bem empregado, funciona como algo que "pode divertir e criar uma impressão duradoura. Contudo, ele pode também destruir a credibilidade, se empregado inapropriadamente" (ARENS; SCHAEFER; WEIGOLD, 2013, p. 234).

Arens, Schaefer e Weigold (2013, p. 246) lembram que, para que os comerciais de TV e anúncios sejam eficazes, é preciso preocupar-se com a impressão final que o comercial provocará; isto é, dar abertura para a atenção "uma abertura visualmente surpreendente, de ação, drama, humor ou interesse humano, determina o contexto, permitindo uma transição tranquila para o restante do comercial [...]". Evitando artificialidade nos anúncios, isso fará com que a situação seja transformada de forma natural na história da venda. Outro fator é o personagem. Para os autores, os personagens são símbolos, por isso, devem ser cativantes e verossímeis, devem ter relevância e não provocar distração (ARENS; SCHAEFER; WEIGOLD, 2013, p. 246). Levando em conta esses conceitos, em especial a naturalização e o humor na propaganda da Dove Men +Care, podemos vê-los como fatores que contribuem e contribuíram para que o público entenda a propaganda como criativa. 


\section{Gramática do design visual de Kress e Van Leeuwen (2006)}

Kress e Van Leeuwen (2006), em Reading Images, adaptam as três metafunções da linguagem verbal descritas por Halliday e Matthissen (2004), as quais podem também ser realizadas por outros modos semióticos. Nesse sentido, aqueles autores descrevem os recursos disponíveis no modo imagético para desempenhar as metafunções. As três metafunções que Kress e Van Leeuwen (2006) descrevem são: ideacional, interpessoal e textual.

A primeira, ideacional, trata da habilidade dos atuantes no processo de significação em representar objetos, ou participantes e sua relação com o mundo. São dois os tipos de participantes envolvidos no ato semiótico: o participante interativo e o representado. $\mathrm{O}$ primeiro consiste nos sujeitos da cultura em que o texto circula: produtor e consumidor. O segundo, participante representado, consiste em pessoas e objetos representados na imagem, desempenhando papéis semânticos definidos. Ainda na função ideacional, o participante interativo informa sobre suas experiências e ações no mundo, utilizando seus participantes representados e, assim, ocorrem eventos ou ações que envolvem os participantes interativos. A partir disso, há processos narrativos, podendo ser distinguidos con- forme o tipo de vetor, número e tipo de participante envolvido. Esses processos narrativos podem ser transacionais ou não transacionais. No primeiro, a ação é feita para alguém ou para algo (ator e meta). Já no segundo, a ação não é feita para alguém ou algo, não há meta ou ela não pode ser identificada (KRESS; VAN LEEUWEN, 2006).

A outra metafunção, interpessoal, diz respeito ao processo de interação entre os participantes interativos, no qual são projetadas relações entre os participantes interativos que estão envolvidos no ato comunicativo, abarcando também a atividade avaliativa do participante interativo, tais como o contato, a distância social, envolvimento, poder, atitude e modalização (KRESS; VAN LEEUWEN, 2006).

A última metafunção, textual, trata das relações da distribuição espacial dos elementos que são retratados, demonstra as relações hierárquicas e funcionais entre os participantes representados. Nela se observa a saliência (contrastes de cor, iluminação, volume); o valor informacional (posicionamento dos participantes no enquadre - centro e margens, direita e esquerda, superior e inferior) e, por fim, a conexão ou desconexão (molduras, espaços vazios ou descontinuidades cromáticas que trazem a desconexão semântica ou retórica entre os elementos representados nos espaços). No Quadro 1 , podemos ver quais as metafunções e 0 que está relacionado a cada uma delas: 
Quadro 1 - categorias centrais das metafunções de Kress e Van Leeuwen (2006)

\begin{tabular}{|c|c|c|}
\hline \multicolumn{3}{|c|}{ METAFUNÇÕES DA GRAMÁTICA DO DESIGN VISUAL } \\
\hline Ideacional & $\begin{array}{l}\text { Participantes Interativos: } \\
\text { os participantes que estão no ato da } \\
\text { comunicação - os participantes que } \\
\text { falam e ouvem ou leem e escrevem, } \\
\text { fazem imagens ou as visualizam. } \\
\text { Participantes representados: } \\
\text { constituem o sujeito - as pessoas, } \\
\text { lugares e coisas- representadas na e } \\
\text { pela linguagem ou a escrita ou a ima- } \\
\text { gem, os participantes sobre quem ou } \\
\text { qual estamos falando ou escrevendo } \\
\text { ou produzindo imagens. }\end{array}$ & $\begin{array}{l}\text { Narrativo } \\
\text { - Processos transacionais } \\
\text { (com meta) } \\
\text {-processos não transacionais } \\
\text { (sem meta) } \\
\text { Bidirecional: } \\
\text { Algumas estruturas funcionam as- } \\
\text { sim quando cada participante atua } \\
\text { entre ator e meta. } \\
\text { Conceitual } \\
\text { retrata o que o participante interativo } \\
\text { tem, ou é. }\end{array}$ \\
\hline Interpessoal & \multicolumn{2}{|l|}{$\begin{array}{l}\text { Contato } \\
\text { Distância social } \\
\text { Poder } \\
\text { Atitude } \\
\text { Modalização }\end{array}$} \\
\hline Textual & \multicolumn{2}{|l|}{$\begin{array}{l}\text { Saliência } \\
\text { composição } \\
\text { Valor informacional } \\
\text { Conexão ou desconexão }\end{array}$} \\
\hline
\end{tabular}

Fonte: a autora (2017).

Feito esse breve resumo das metafunções, estamos em posição de sintetizar a proposta de analisar multimodalmente 0 anúncio Dove Men + Care, observando a temática gênero.

\section{Análise multimodal do anúncio}

A campanha publicitária "Slow" Dove Men + Care é um anúncio audiovisual que foi lançado em março de 2013, com um minuto e sete segundos de duração, que divulga um produto novo da Unilever ao público masculino, mais especificamente um shampoo. $\mathrm{O}$ vídeo/anúncio mostra um homem de cabelo comprido, chamado Diego, que ao ser abordado por um colega no ambiente de trabalho exibe seus cabelos brilhantes e macios, como se fosse uma personagem de um comercial de shampoo feminino ${ }^{13}$.

A propaganda inicialmente foi produzida para ser veiculada no YouTube, mas depois acabou sendo veiculada também como comercial de TV. Nas redes sociais, 
a propaganda teve muitas visualizações, gerando grande repercussão, inclusive negativa, já que parte do público a julgou como sendo sexista ${ }^{14}$. Na ocasião, alguns vídeos respostas foram criados criticando o tom de que homens de cabelo comprido e que usam shampoo feminino seriam feminizados.

A narrativa ocorre da seguinte forma: ao personagem Diego ser alertado sobre o "visual estranho", provavelmente provocado pelo uso de produtos específicos para os cabelos das mulheres, se desespera. No mesmo instante, pula da cadeira e, com os cabelos lindos, longos e sedosos, corre para o supermercado em busca do produto Dove Men + Care. Ao lavar o cabelo com o shampoo que comprou, seu cabelo volta a ser curto e com menos movimentos.

Para facilitar a compreensão, transcreveremos na sequência a fala dos personagens na narrativa e, depois, apresentaremos os frames do anúncio.

\section{Transcrição do áudio}

Ator coadjuvante/ colega: (5 segundos) - "Ô Diego... (pausa longa com música remixada ao fundo) "

Diego: (9 segundos) - "Oi? (pausa curta sem som, pausa longa com música no fundo. Neste momento os dois participantes ficam se olhando)"

Ator coadjuvante/ colega: (16 segundos) "Você fez alguma coisa no cabelo?"

Diego: (22 segundos) "Não".
Ator coadjuvante/ colega: (24 segundos) - "É que ele tá com efeito de comercial de shampoo de mulher... quando você .. faz assim..."

Diego: (31 segundos) - "Sério?!" (background com música e o Participante representado vê o cabelo como se fosse comercial de shampoo feminino)

Ator coadjuvante/ colega: (37 segundos) - "Deve ser o Shampoo que você tá usando" (há um feedback do personagem lembrando-se do momento que lavou o cabelo com shampoo feminino. Quando se dá conta, ele "corre" para o mercado para comprar um shampoo para cabelo masculino. Já no outro fra$m e$, o personagem lava o cabelo com o Dove Men + Care e durante o trajeto e o tempo no chuveiro a música remixada ${ }^{15}$ fica ao fundo)

Narrador /locutor: ( 1 min e 4 segundos) - "Shampoo feminino não foi feito para você. Dove Men + Care foi!" (Na diegese ocorre a "troca" do shampoo feminino pelos shampoos da linha Dove Men + Care)

\section{Principais frames}

Para facilitar a compreensão da análise do anúncio, dividimo-lo em frames (23, no total), os quais marcam as partes mais salientes do anúncio, isto é, os momentos do vídeo em que se percebem as performances (ethos) dos personagens num paradigma masculino versus feminino. 

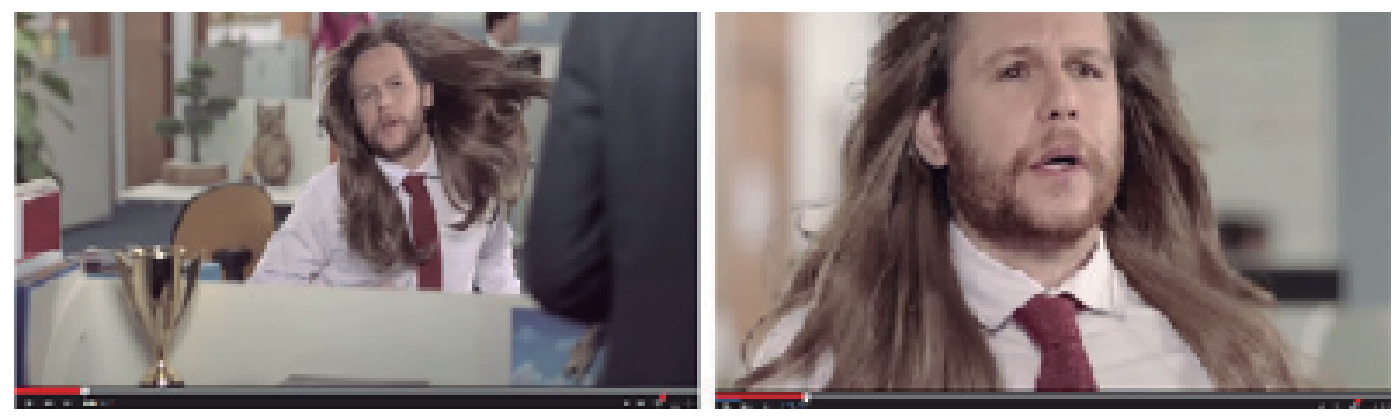

1

2
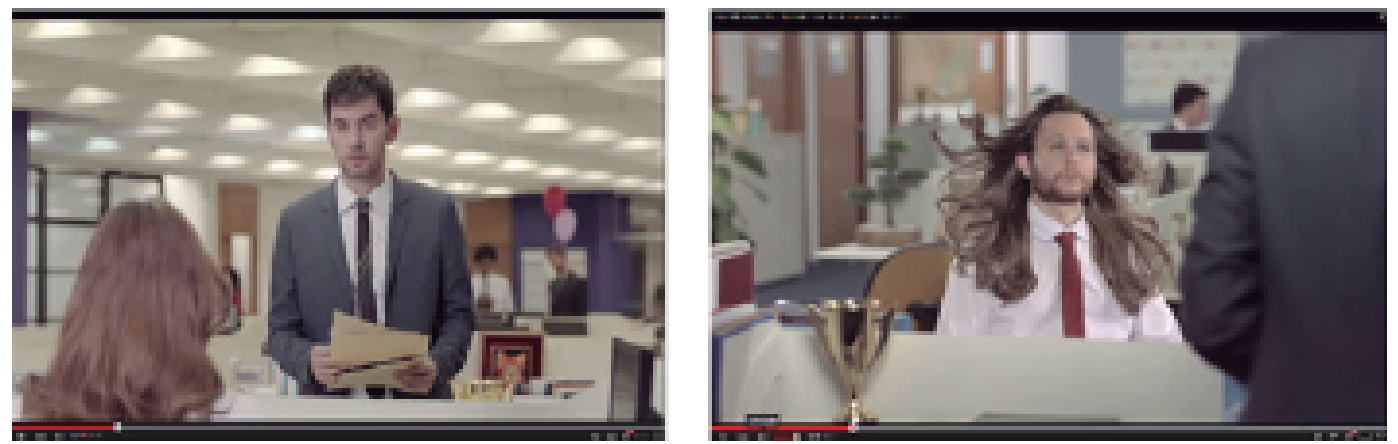

3

4
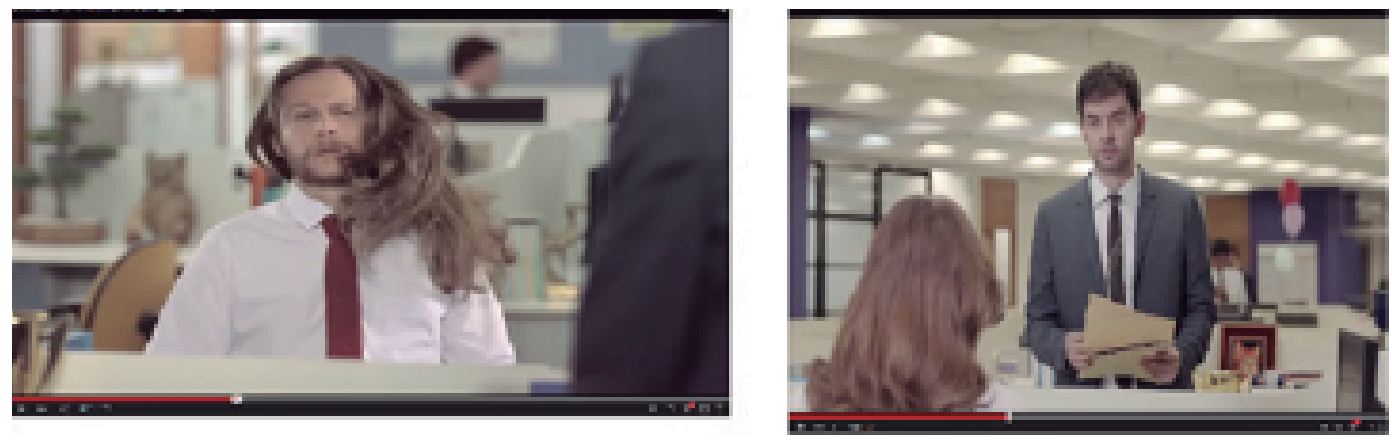

5

6

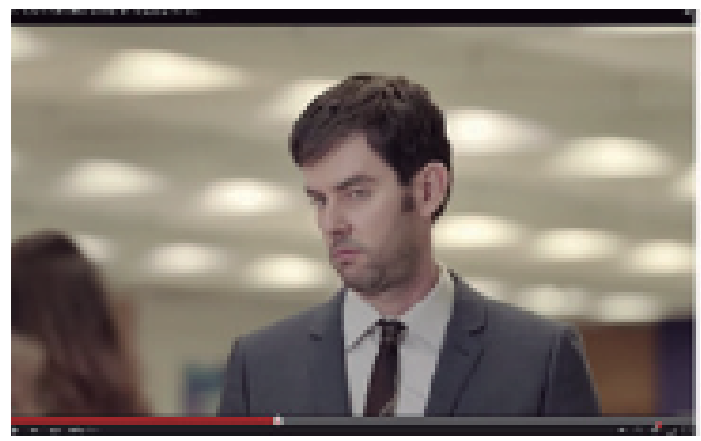

7

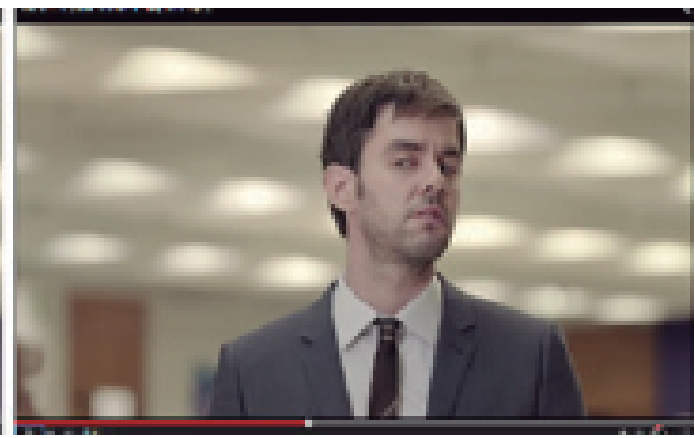

8 


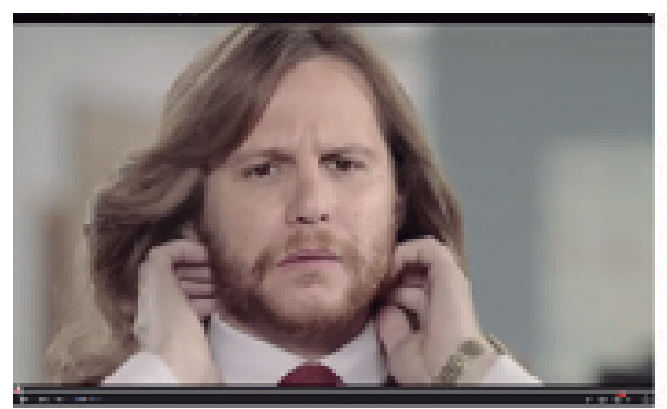

9

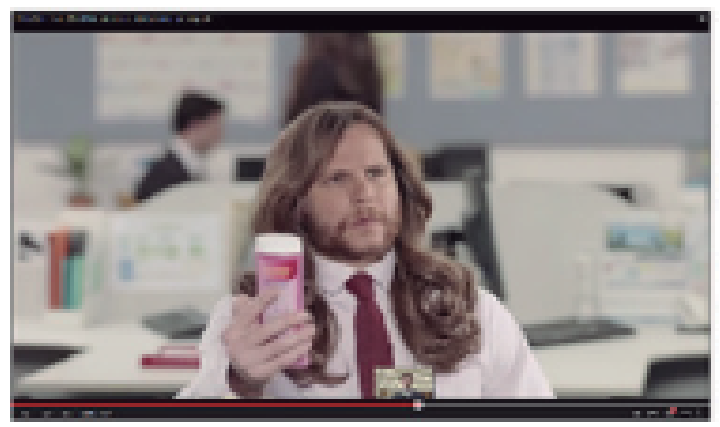

11

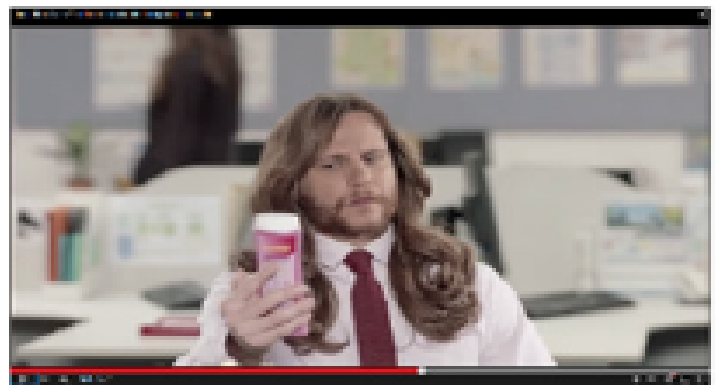

13

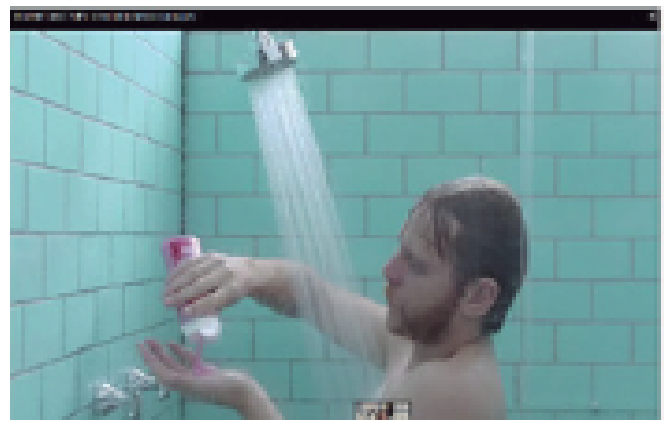

14

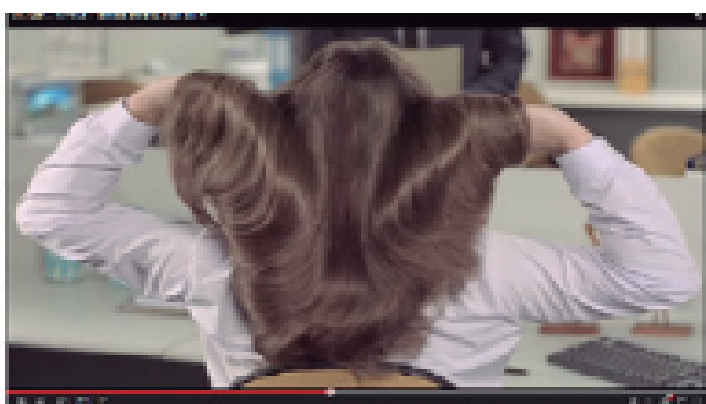

10

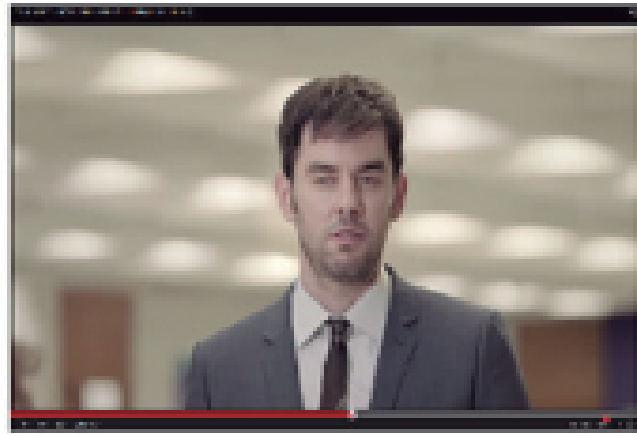

12

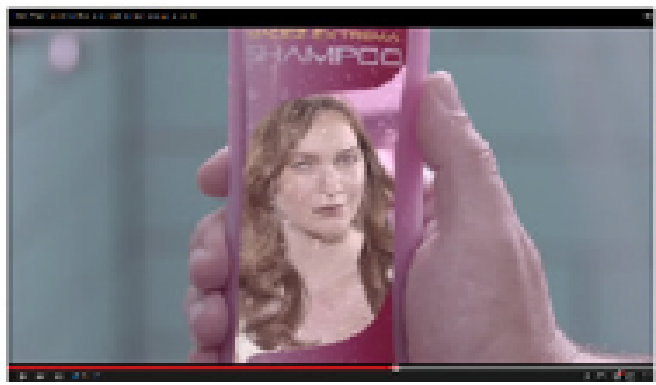

14

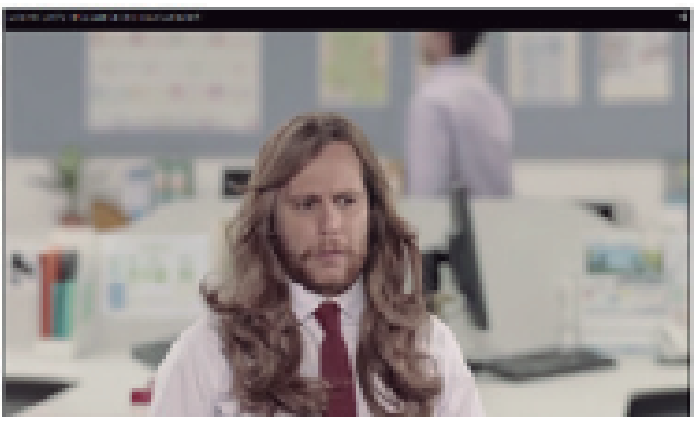

15 

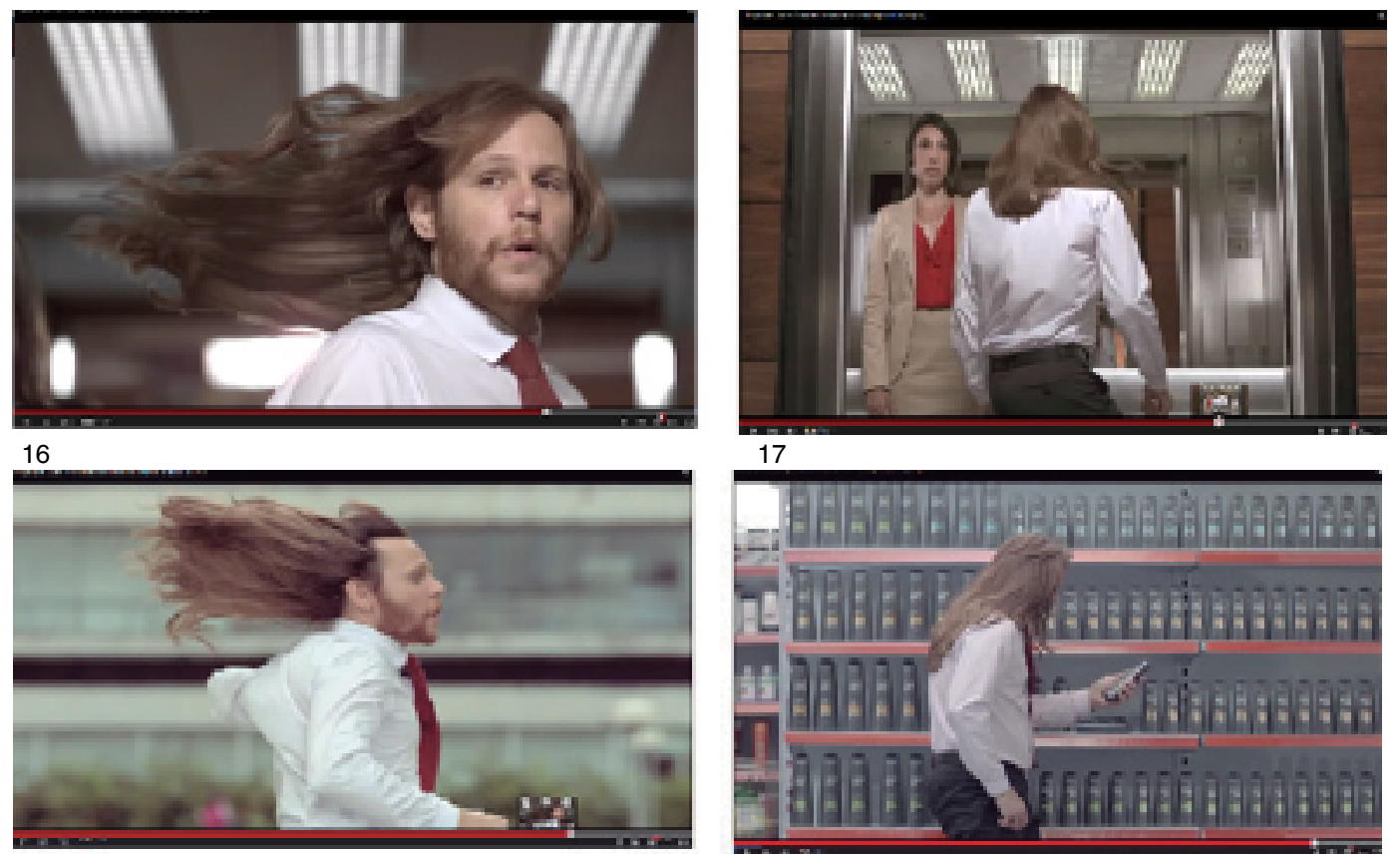

18

19
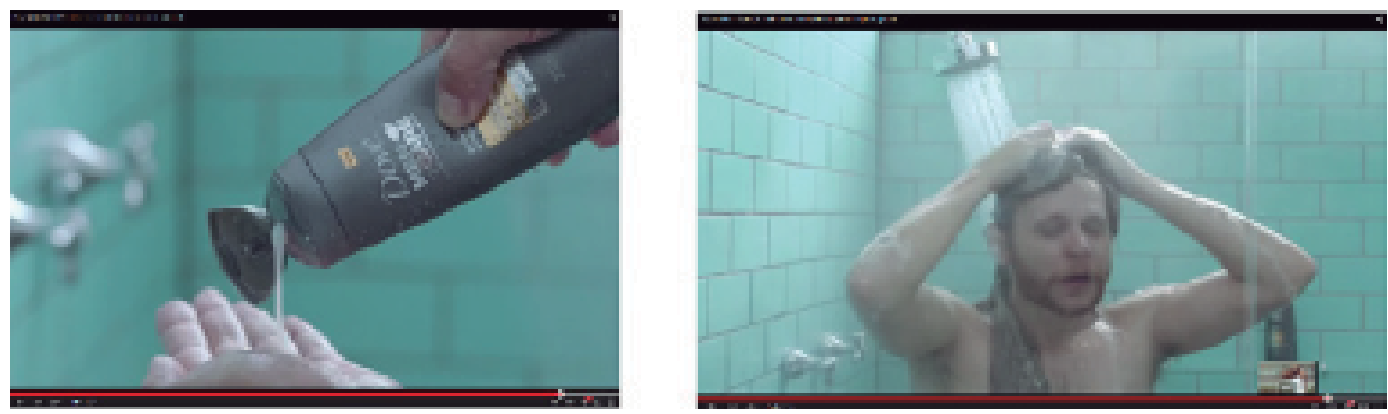

20

21

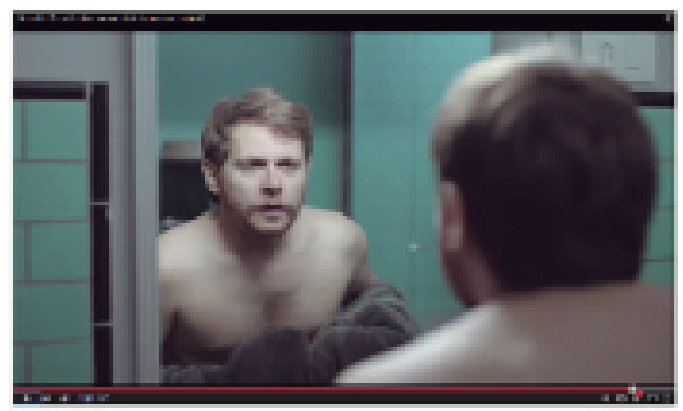

22

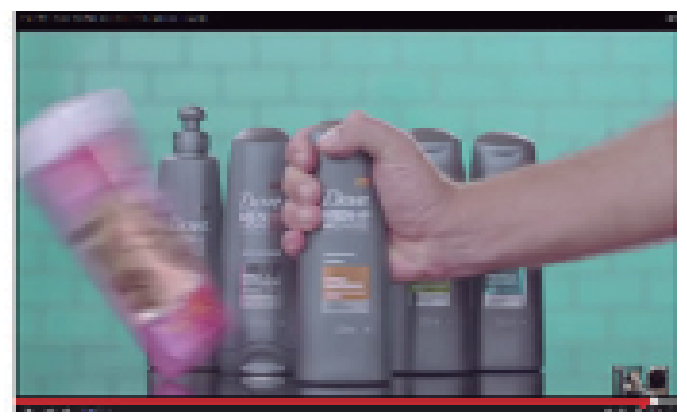

23 
Tendo os frames ${ }^{16}$ e o áudio aqui sinalizados, agora poderemos fazer a análise a partir das três metafunções: ideacional, interpessoal e textual.

\section{Metafunção ideacional}

A metafunção Ideacional ajuda a compreender quem são os sujeitos, ou seja, é responsável por descrever os participantes quanto à ação que desenvolvem em uma imagem. Dessa forma, no anúncio Slow: Dove Men + Care, temos como participante representado (pessoas, lugares e coisas) o Diego (ator) (frames 1 e 2). Trata-se de um processo transacional, pois observando os frames $(3,4,5,6,7$ e 8$)$ encontramos que Diego (personagem) atua como um ator da ação de conversar com o colega, que é a meta. Esse mesmo processo também pode ser observado nos frames (13 e 14), em que, por meio do olhar, o ator Diego interage com o shampoo (meta).

Kress e Van Leeuwen (2006) usam o termo narrativa para contrastá-lo a eventos conceituais. Assim, nos padrões conceituais os participantes não estão em ação, no geral têm uma essência estável e atemporal, enquanto que nos padrões narrativos os participantes servem para apresentar ações que culminam em eventos, processos de mudança e, por isso, são transacionais. Os autores destacam que são padrões vetoriais da narrativa. Por isso, o que faz uma proposição visual ser narrativa é a presença de um vetor. Nas estruturas narrativas eles estão presentes, ao passo que, nas conceituais, não. Nas imagens, os vetores são geralmente formados por elementos que formam uma linha oblíqua; no caso do anúncio, a mão do personagem e o braço, assim como o cabelo, também são vetores (frames 9, 10,11, 12,14 ${ }^{17}, 19,20$, 21 e 23).

É importante salientar que nas imagens em movimento nem sempre os eventos têm um ator e um alvo como nas imagens estáticas. Conforme Maia e Pimenta (2014, p. 138), na dimensão interativa as posições da câmera "criam relações simbólicas entre os observadores e o que é retratado em uma imagem. No caso da imagem em movimento esse relacionamento torna-se dinâmico". Assim sendo, percebemos que com o vetor isso também acontece no anúncio que analisamos, em atenção aos frames (10 e 11), que são a sequência da narrativa.

Além disso, o próprio movimento dos vetores - mão e braço - feito conforme os frames (9 e 10), indicia, de forma irônica, que o ator está reproduzindo estereótipos de comerciais de produtos femininos, já que homens usam qualquer outro shampoo, mas Diego, por usar o cosmético feminino, age como mulher, por isso o produto faz o personagem agir como mulher. Diferentemente do que é preconizado socialmente, pois há, na memória de representação do masculino, o estereótipo do homem de cabelo curto, como o que é apresentado no final, depois de o personagem lavar seus cabelos com o shampoo Dove Man Care. Como afirma 
Kiesling (2007, p. 659), os recursos de linguagem são marcados por atitudes que indiciam "certos tipos de homens".

\section{Metafunção interpessoal}

Esta é a metafunção responsável por descrever as relações de interação construídas pela imagem. Conforme Pinheiro (2015, p. 220), baseia-se "na construção da atitude orientacional em relação a destinatários e públicos presentes e potenciais, e em relação ao conteúdo ideacional dos discursos, no que diz respeito às relações e avaliações sociais a partir de um ponto-de-vista particular". A identidade do personagem é social e ideologicamente construída para o interlocutor/telespectador desde a escolha do modo verbal e sonoro, quando marca o estereótipo de feminilidade. Isso é marcado quando o ator coadjuvante diz: "É que ele tá com efeito de comercial de shampoo de mulher". Dessa forma, durante toda a narrativa, por meio do recurso da intertextualidade ${ }^{18}$, ocorre uma comparação entre o cabelo do ator e o de uma atriz de um comercial do mesmo ramo, evidenciando um ponto de vista particular.

Assim, o espaço do escritório é uma forma de ambientação para mostrar os lugares sociais em que as diferenças são sinalizadas, neste caso o trabalho, já que acontecem situações corriqueiras em que os colegas observam uns aos outros por meio de atitudes e comportamentos. A partir do momento em que o colega do Diego afirma que seu cabelo está com efeito de comercial de shampoo de mulher (frames 7, 8 e 9), em consonância com os efeitos sonoros, entre a pausa do som e os movimentos do cabelo (frames 4,56 e 10), percebemos que o personagem se sente acuado por estar com os cabelos lindos e sedosos (já que isso seria representação de feminilidade). Apelando para o recurso do riso/humor, como assinala Lipovetsky (2005, p. 115),

[...] atualmente estamos além da era satírica e da sua comicidade mordaz. Por meio da publicidade, da moda, dos aparelhos eletrônicos, dos desenhos animados e dos quadrinhos quem não percebe que o tom dominante e inédito do cômico já não é o sarcástico, mas, sim, lúdico? (LIPOVETSKY, 2005 , p. 115 , grifos do autor).

A esse propósito, Moita Lopes (2006), ao propor a discussão que as masculinidades mudam, recorre a Hall (1999), afirmando que as práticas discursivas nas quais atuamos têm a ver com o tornar-se e não com ser. Para o autor, estamos presenciando um momento de mudança no que se entende por masculinidade hegemônica, no sentido de que a masculinidade também pode ser heterogênea. Mas o discurso do anúncio fica enviesado a partir do momento que tenta impor (enquanto mídia) um padrão de masculinidade hegemônica, já que, a partir do momento em que o personagem lava o cabelo com Dove Men+ Care (frames 20, 21 e 22), deixa de ter o cabelo comprido e sedoso e passa a ter cabelo de homem: curto e com pouco movimento.

No que tange às categorias de análise da metafunção Interpessoal, destacaremos os pontos de imagens: contato 
(participantes representados olham diferentemente para os olhos do espectador, e imagens nas quais isso não acontece), distância social (máxima, média ou mínima entre PR e PI) e o envolvimento/ perspectiva (ângulo em que os $\mathrm{PR}$ se apresentam na imagem) (KRESS; VAN LEEUWEN, 2006).

No caso do contato, pode ser visto pela linha do olhar e ser entendido se os olhos se direcionam ao leitor/observador (frames 2, 5 e 11), ou como se a linha do olhar tem um alvo que podemos depreender pela imaginação (15, 16 e 22). Sendo assim, percebemos que o contato é feito por meio da oferta, já que o participante representado não olha diretamente para o seu leitor, sendo oferecido como objeto de análise.

No caso da distância social ela é percebida pela escolha que se pode fazer entre o plano fechado (close-up), plano médio (médium shot) e plano aberto (long shot) (KRESS; VAN LEEUWEN, 2006). No plano fechado, temos os frames 11, 13 e 20 como exemplo. Já para plano médio há vários enquadres como os frames $1-9 ; 12$ e 13; 15, 16, 18, 21 e 22. O plano aberto pode ser visto pelos frames 17,18 e 19 .

O envolvimento dá-se por três ângulos, os quais definem a subjetividade da imagem em relação aos seus espectadores: ângulo frontal, ângulo oblíquo e ângulo vertical. O primeiro, no nível do olhar do participante interativo, ângulo frontal, não aparece nas imagens. $O$ segundo, ângulo oblíquo, que transmite sentido de desconexão são encontrados nos frames 1, 2, 5, 15 e 16, revelando que o que está sendo observado pelo PI não lhes pertence e nem pertence ao seu mundo. Por último, o ângulo vertical, dividido em ângulo alto e ângulo baixo, ocorre pelas diversas relações de poder que são possíveis entre PR e PI. Como ângulo alto podemos observar os frames $4,6,7,15$ e 21, como ângulo baixo o 17 . Assim sendo, observa-se que a maioria dos enquadres feitos são com ângulos planos, já que o objetivo da propaganda é dialogar com o participante interativo. Conforme Iedema (2001), a semiótica social centra na questão de como observador é posicionado pelo vídeo em questão, e de como o observador vê certas fidelidades e valores sociais sendo promovidos em detrimento de outros. No caso do audiovisual em análise, os enquadres planos levam o leitor a, enquanto observador, sentir-se mais próximo do texto, convidando-o a partilhar da experiência de utilizar o shampoo Dove Man Care.

\section{Metafunção textual}

Essa é que organiza e estrutura os elementos na imagem. Desse modo, no anúncio que estamos analisando, percebem-se formas de caracterização do masculino e feminino, colocando-os num contorno binário e operando com comunicações distintas para ambos. Essa distinção entre sexos é fruto de uma trajetória histórica e cultural, não só do mercado publicitário, mas também da 
sociedade que trabalha com os estereótipos de feminilidade e masculinidade. Trata-se, portanto, da representação do que é o estereótipo de masculinidade. No nosso caso, se observarmos a função do shampoo que é limpar o couro cabeludo, não há necessidade de desenvolver um produto diferenciado para homens e mulheres. Mas o modelo atual da sociedade do consumo acha nichos no mercado para encontrar um público-alvo e criar as diferenças. Logo, o anúncio busca falar diretamente com o homem, participante interativo (geralmente produtor e observador). Para Iedema (2001), a diegese pontua a diferença entre o que está implícito na imagem em movimento, o que está acontecendo no tempo real e o que as imagens realmente mostram.

O próprio slogan: "shampoo feminino não foi feito para você! Dove Men Care foi." apela para o que Benhabib (1987) entende como sistemas gênero - sexo conhecidos historicamente e que contribuem para a opressão e exploração das mulheres. Nesse caso, acrescentaríamos dizendo que funciona como critério de exclusão não só de mulheres, mas de homens também.

Isso posto, encontramos na diegese uma busca de validação para o que é socialmente definido para homens e o que é definido para mulheres em relação aos recursos imagéticos, produzindo a diferença de gênero. Já que na narrativa, o gênero é "o modo como os corpos são trazidos para dentro da história: os corpos são arenas para a construção dos padrões de gênero" (CONNELL, 2000, p. 12).

\section{Conclusão}

A partir do que foi visto em nossa análise, percebemos que a modalidade imagem em movimento carrega recursos disponíveis e ferramentas que projetam e redesenham identidades, numa construção discursiva, propondo à sociedade a adoção de ideologias ou filosofias de vida. Identificamos com a análise multimodal, por meio das metafunções ideacional, interpessoal e textual que conseguir ler criticamente as imagens significa verificar modos de pensar da sociedade sobre o que é comum em uma ou outra identidade de gênero - forma como a pessoa se identifica - para a cultura brasileira.

Destacamos que os enquadres em planos médio e aberto refletem o grau de intimidade entre os participantes da narrativa, oscilando entre o intermediário e o distanciamento. $\mathrm{O}$ que resulta uma relação de desconhecimento do poder entre participantes representados e participantes interativos.

Com a metafunção ideacional entendemos que os participantes que são representados na narrativa do comercial da Dove, em especial Diego, representam os homens que que vivem em um contexto basicamente masculino e que são questionados sobre suas escolhas físicas, pois a própria apresentação de seu cabelo (como vetor) em formato de " $u$ ", apresentando um bom caimento, 
indicia para o que é típico de um cabelo de comercial de shampoo feminino, isto é, o estereótipo do cabelo liso, comprido e sedoso, estando, além disso, com uma cor característica, que é o loiro escuro.

Pela metafunção interpessoal, é possível verificar que a produção do audiovisual preocupou-se em envolver o participante interativo, instigando a figura masculina, que estivesse assistindo a narrativa, a identificar-se com o participante representado, sentindo a necessidade, em detrimento dos arranjos sociais estabelecidos, de usar um shampoo destinado ao público masculino. Para tanto, utiliza-se da perspectiva e do envolvimento que é feito pela maioria dos frames apresentados por ângulos planos, convidando o público masculino a experimentar o novo produto, feito exclusivamente para homens.

Se pelas metafunções ideacional e interpessoal conseguimos identificar os sentidos sugeridos pelo comercial sobre o que é usar um produto que não seja essencialmente feito para um público "x", nesse caso, o público masculino; a metafunção textual permite ao leitor concluir que de fato, há um desejo de segmentação do público-alvo para esse tipo de mercadoria, a fim de ampliar a possibilidade de venda, gerando lucro, por meio de preferencias e particularidades sugeridas, não só pelo modo visual, sonoro, ou gestual, mas também pelo modo verbal, que o "coroa" a fusão desses modos, contribuindo para a desigualdade, ao fechar o comercial com o slogan "Shampoo feminino não foi feito para você, Dove men care, foi."

Assim sendo, ao mesmo tempo, quando o mercado busca criar a exclusividade de um público-alvo para determinado produto, acaba por proporcionar espaço para a exclusão, criando desdobramentos em diferentes contextos. Entre o humor e estereótipos, as práticas sociodiscursivas das quais participamos na vida cotidiana carregam no seu interior convenções do que é masculinidade e feminilidade, realizando-se sempre por meio da linguagem.

Por fim, com este trabalho, entendemos no mesmo sentido de Kress e Van Leeuwen (2006) que as estruturas visuais não são simples reproduções de estrutura da realidade, pois ao se produzir imagens da realidade, nelas estão vinculados interesses de instituições sociais em que as imagens são produzidas e estão circulando. Por isso, são ideológicas e possuem uma dimensão semântica de profunda importância.

\section{Humor and stereotypes on YouTube: a critical multimodal analysis of the advertisement "Slow dove men + care"}

\section{Abstract}

This article aims at identify how the notion and the relation of gender are multimodally built in a widely broadcasted audiovisual advertisement in 2013, on the YouTube, called "Slow: Dove Men + Care. In order to achie- 
ve this goal, the theoretical-analytical Social Semiotic approach was employed. The multimodal analysis has specifically addressed the on three metafunctions of The Grammar of Visual Design (Reading Images): ideational, interpersonal and the textual. With the discussion about gender and the analysis of the advertisement, it was noted that as stereotypes are created and presented in the media, the values society advocate are evinced, since they are embedded in these discourses, behaviors, values and attitudes regarding one gender or the other, formulating postures of masculinity or femininity and relations of power between them.

Keywords: Multimodality. Gender. Audiovisual advertisement. Stereotypes.

\section{Notas}

1 O presente trabalho foi realizado com apoio da Coordenação de Aperfeiçoamento de Pessoal de Nível Superior - Brasil (CAPES) - Código de Financiamento 001

2 Disponível em: <http://www.ogilvy.com.br/>. Acesso em: 22 jun. 2015.

3 Consiste em um movimento de estudo para empresas que decidem empreender e desejam colocar um novo produto em circulação. Dessa forma, a pesquisa mercadológica pode contribuir para ajudar a identificar possíveis problemas e também oportunidades, buscando conhecer o perfil do cliente quanto ao estilo de vida, características comportamentais, hábitos de consumo, escolaridade, renda, entre outros. Fonte: <http://www.sebrae.com.br/sites/PortalSebrae/artigos/pesquisa-de-mercado-o-que-e-e-para-que-serve,97589f857d545410VgnVCM 1000003b74010aRCRD> Acesso em: 31 maio 2017.

4 Disponível em: <http://www.dove.com.br/pt/ Produtos/MenCare/default.aspx > Acesso em: 25 jun. 2015.

5 Disponível em: <http://www.adnews.com.br/ publicidade/ogilvy-mostra-que-shampoo-de-mulher-nao-e-para-homem>. Acesso em: 23 jun. 2015.
6 Compreendo estereótipo como imagens mentais criadas pelo sujeito a partir de uma divisão de traços comuns a um evento vivido anteriormente. Conforme Martino (2009, p. 21), "a partir da experiência com alguma pessoa ou ambiente constrói-se um estereótipo ou representação que permite identificar situações semelhantes e aplicar elas a representação anterior".

7 Disponível em: <https://www.youtube.com/ watch?v=J-38HR0m_iA >. Acesso em: 15 jun. 2015.

8 Tradução nossa.

9 Entendemos aqui o índice como significado de determinados símbolos, relacionados à palavras, à aproximação corporal, gestos etc.

10 A mídia social é o meio pelo qual a informação é veiculada. A mídia social dispõe de ferramentas as quais facilitam a comunicação entre os usuários, integram o conteúdo gerado pelos próprios usuários, com postagem de mensagens instantâneas e textos, compartilhamento de vídeos, áudios e imagens. (CIRIBELI; PAIVA, 2011).

11 Informacões obtidas de: <http://pt.wikipedia. org/wiki/YouTube>. Acesso em: 14 jun. 2015.

12 Informações obtidas de: <http://pt.wikipedia. org/wiki/AdSense>. Acesso em: 14 jun. 2015.

$13 \mathrm{O}$ vídeo foi produzido pela empresa Ogilvy e Mather, conhecida como a segunda maior agência do país que, em 2013, foi eleita a Agência do Ano no Festival de Cannes.

14 Disponível em: https://www.youtube.com/ watch? $\mathrm{v}=\mathrm{xEVyOwP5mBk}$. Até a produção deste texto, o audiovisual teve um total de 11.670 visualizações. Também, vale destacar que um vídeo de resposta que está disponível na rede tem mais de 180 mil "views"(visualizações).

15 A música de fundo é de um quarteto feminino, The Saturdays, intitulada Notorious e foi remixada para a própria propaganda. Não é nosso objetivo aqui nos debruçar no modo sonoro, mas no visual. Apesar disso, importa dizer que a letra da música fala de uma mulher que quer dominar o espaço e sua relação com os homens.

16 Os frames foram feitos a partir do vídeo veiculado no próprio YouTube. Disponível em: $<\mathrm{https}$ :// www.youtube.com/watch?v=J-38HR0m_iA $>$ Acesso em: 15 jun. 2015.

17 No caso do frame 14, temos duas, pois a segunda é o zoom.

18 Referimo-nos àqueles comerciais como alguns das marcas Seda, Elseve L'Oréal Paris em que as modelos são apresentadas ao leitor com o cabelo perfeito, com movimento e brilho. Ex. <https://www.youtube.com/ watch?v=Wlgt4LrmE2U>; <https://www.youtube.com/watch?v=tG9FwUuxREg $>$. Acesso em: 05 jun. 2017. 


\section{Referências}

ARENS, William F.; SCHAEFER, David H.; WEIGOLD, Michael F. Propaganda. Porto Alegre: AMGH, 2013.

BENHABIB, Seyla. Critique, norm, and utopia: a study of the foundations of critical theory. New York: Columbia University Press, 1986.

Sexual difference and collective identities: the new global constellation. Signs. v. 24, n. 2,1999 , p. $335-361$.

BUTLER, Judith. Problemas de gênero. Rio de Janeiro: Civilização Brasileira, 2003.

. Sexual politics, torture, and secular time. The British Journal of Sociology. v. 59, n. 1, 2008, p. 1-23. Disponível em: <http:// onlinelibrary.wiley.com/doi/10.1111/j.14684446.2007.00176.x/abstract>. Acesso em: 24 jun. de 2015.

. Gender Trouble: Feminism and the Subversion of Identity. New York: Routledge, 1990.

CAMERON, Deborah. Desempenhando identidade de gênero: conversa entre rapazes e construção da masculinidade heterossexual. In: OSTERMANN, A.; FONTANA, B. Linguagem. Gênero. Sexualidade. Clássicos traduzidos. São Paulo: Parábola Editorial, 2010.

CIRIBELI, João Paulo; PAIVA, Victor Hugo Pereira. Redes e mídias sociais na internet: realidades e perspectivas de um mundo conectado. Revista Mediação. v. 13, n. 12, jan. / jun. de 2011. Disponível em: <http://www.fumec.br/revistas/mediacao/article/view/509>. Acesso em: 31 maio 2017.

CONNELL, Raewyn. The Men and the Boys. Sydney, Allen e Unwin; Cambridge, Polity Press; Berkeley, University of California Press, 2000.

HALLIDAY, Michel; MATTHIESSEN, Christian. An introduction to functional grammar. 3. ed., London: Hodder Education, 2004.
HALL, Stuart. A identidade cultural na pós-modernidade. Rio de Janeiro: DP\&A, 1999.

IEDEMA, Rick. Analysing film and television: a social semiotic account of Hospital: an Unhealthy Business. In: VAN LEEUWEN, T.; JEWITT, C. (Ed.). Handbook of visual analysis. London: SAGE Publications Ltd, 2004.

JEWITT, Carey.; OYAMA, Rumiko. Visual meaning: a social semiotic approach. In: VAN LEEUWEN, Theo.; JEWITT, Carey. (Ed.). Handbook of visual analysis. London: SAGE Publications Ltd, 2004.

KIESLING, Scott. Men, Masculinities, and Language. Language and Linguistics Compass,v. 1, Issues 6, p. 653-673, November, 2007. Disponível em: <http:// onlinelibrary.wiley.com/doi/10.1111/j.1749818X.2007.00035.x/abstract>. Acesso em: 25 jun. 2015.

KRESS, Gunther; VAN LEEUWEN, Theo. Reading images: the grammar of visual design. London; New York: Routledge, 2006 [1996].

MANO, Vinicius. $O$ processo criativo na publicidade interativa. Dissertação de Mestrado em Ciências da Comunicação - Audiovisual e Multimídia, Universidade do Minho, Instituto de Ciências Sociais, junho 2009. Disponível em: <http://repositorium.sdum. uminho.pt/bitstream/1822/10389/1/tese.pdf>. Acesso em: 14 jun. 2015.

MANOVICH, Lev. The language of new media. Cambridge: MIT Press, 2002.

MOITA LOPES, Luiz Paulo. "Falta homem até pra homem": A construção da masculinidade hegemônica no discurso midiático. In: HEBERLE, V.; OSTERMANN, A.; FIGUEIREDO, D. (Org.). Linguagem e Gênero no trabalho, na mídia e em outros contextos. Florianópolis: Editora da Ufsc, 2006.

Discurso, corpo e identidade: Masculinidade hegemônica como comunidade imaginada na escola. Gragoatá, Niterói, v. 11, p. 207-226, 2001. 
PIMENTA, Sônia Maria de Oliveira.; MAIA, Denise Giarola. Multimodalidade e letramento: análise da propaganda Carrossel. Revista Desenredo, v. 10, n. 1, 2014. Disponível em: <http://www.upf.br/seer/index.php/rd/article/ view/4100/2644>. Acesso em: 12 jun. 2015.

PINHEIRO, Petrilson Alan. Construção multimodal de sentidos em um vídeo institucional: (novos) multiletramentos para a escola. Veredas atemática, Minas Gerais, v. 19, n. 2, 209-224, 2015. Disponível em: <http://www.academia.edu/12353764/ CONSTRU\%C3\%87\%C 3\%830_MULTIMODAL_DE_SENTIDOS_EM UM_V\%C3\%8DDEO_INSTITUCIONAL_ NOVOS_MULTILETRAMENTOS_PARA_A_ ESCOLA $>$. Acesso em: 22 jun. de 2015.

SISSORS, Jack Zanville. Planejamento de mídia. Jack Zanville Sissors; Lincoln Bumba. Trad. Karin Wright. São Paulo: Nobel, 2001. 